\title{
Reliability Centered Maintenance Used in Metro Railways
}

\author{
Shashi B. Singh ${ }^{1}$, Ramu Suresha ${ }^{2}$, Krishnamurthy H. Sachidananda ${ }^{2 *}$ \\ ${ }^{1}$ Manipal Academy of Higher Education, Dubai 345050, UAE \\ ${ }^{2}$ School of Engineering and IT, Manipal Academy of Higher Education, Dubai 345050, UAE
}

Corresponding Author Email: sachidananda@manipaldubai.com

https://doi.org/10.18280/jesa.530102

Received: 18 September 2019

Accepted: 8 November 2019

\section{Keywords:}

reliability, maintenance, predictive, fault, railways, condition based maintenance $(C B M)$

\section{INTRODUCTION}

Maintenance of railways is one of the most complicated and challenging tasks to be carried out by railway infrastructure managers worldwide and huge efforts is required in terms of time and costs. In this context railways services needs to be highly reliable and the equipment and appliances must be kept in good working conditions and hence requires regular maintenance [1]. So, innovative maintenance solutions for railway systems is needed to integrate maintenance and operation in order to ensure safety management of the railways as well as rolling stock [2]. The common approach used in the railways systems are the preventive railway maintenance, corrective railway maintenance and the predictive railway maintenance and is as shown in Figure 1 and general concept of predictive maintenance is as shown in Figure 2.

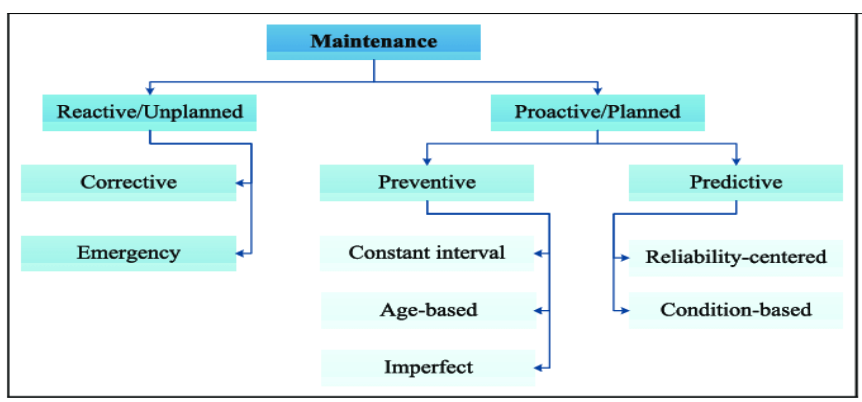

Figure 1. Type of different maintenance followed in railway systems

Preventive railway maintenance is a piece of work regularly performed in order to monitor the situation (Status) or the conditions of a railway equipment in order to reduce the chances of failure [3]. This can be recognized based on identification of bad health of an equipment and preventive measures taken for better reliability of the whole system [4].
Corrective maintenance is a task which is usually done to identify, isolate and resolve a fault. This failed or fault equipment can be replaced or restored to an operational condition within the limits established for in-service operations [5, 6]. Predictive maintenance techniques are commonly designed in order to determine and predict the condition of failures and detailed forecast is ensured and this approach helps the companies in saving cost $[7,8]$.

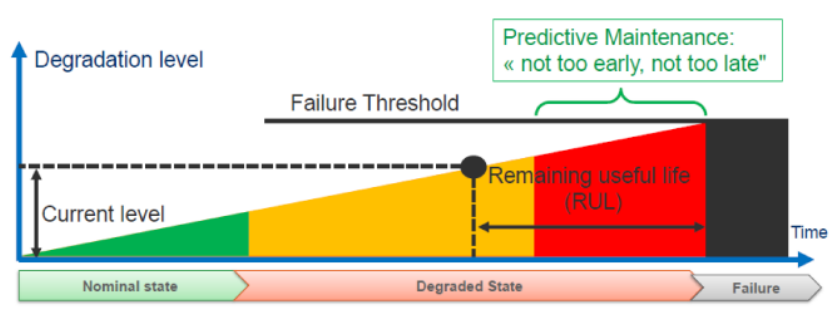

Figure 2. General concept of Predictive maintenance

Pedregal et al. [9] has studied predictive maintenance of a point mechanism of railway systems. They have studied systems safety, reliability, and quality in a railway system considering predictive maintenance using two different RCM techniques considering remote condition monitoring and reliability centered maintenance. Using these models, they concluded that it could detect the failures in the system by analyzing the differences between the real-time data and a reference data. This model consist of two time series data, one of which is a reference data and the second one is the real time data, once the point conditions are changing, the parameters in the reference and real-time data is changing and a threshold has been set to pick-up the changes if it is more than a certain level, which ultimately helps the maintainers to prevent the 
faults before it happens. Marquez et al. [10] has studied a reliability centered approach in order to study remote condition monitoring and developed an algorithm to detect the faults of railway turnouts at its early stages and aimed to move towards $\mathrm{RCM}_{2}$ approach for the maintenance of switches and crossings. There main aim is to find out the benefit of Kalman filter for preprocessing the data, mainly to increase the reliability of the model. They concluded that using Kalman filter the reliability of detecting fault was increased from $97.33 \%$ to $100 \%$ in-reverse to normal direction, while in normal to reverse direction the reliability for detecting irregularities in curve was $94.2 \%$

Ruijters et al. [11] has studied the effect of various maintenance strategies in case of electrically insulated railway joint which is a critical asset in railroad tracks for train detection, and a commonly cause for train disruptions. During this study they considered the Insulated joint as a starting point of fault maintenance tree and they tried to optimize the maintenance using key performance indicators such as reliability, failure count and cost. They concluded that the analysis of the rail joint via fault maintenance tree was constructed with positive result and this maintenance strategy is cost effective. Bertling et al. [12] has studied a reliability centered asset maintenance method on power distribution system to determine the effect of different maintenance strategies on system reliability and cost. They used system reliability analysis, component reliability modelling and cost benefit analysis. They concluded that doing maintenance in the traditional way will cost more, while if RCAM technique is used, it is possible to reduce the cost. Wang et al. [13] has studied the feasibility of applying the Reliability-Centered Maintenance (RCM) system in case of high-speed trains and tried researching few problems, such as fault in assortment, effect as well as fault law, maintenance mode, maintenance task type etc. They also analyzed the impact of RAMS factors considered during designing phase on RCM. They concluded that considering RAMS factor during designing phase helps making a solid pathway to implement the RCM. They also concluded that the RCM approach for maintenance is feasible and reasonable and advised that the RCM study must be carried out on various EMUs and adopted.

Rezvanizaniani et al. [14] has studied the benefits of the RCM for Rolling stock wheel during scheduled preventive maintenance in order to avoid the erroneous maintenance, unnecessary maintenance and to make the maintenance cost effective considering safety as the significant factor in rolling stock. The research was done for wheel set of rolling stock at raja passenger train corporation. They identified and concluded that following the RCM practices there are maintenance task for which the time schedule can be adjusted, and few maintenances can be omitted using this approach and it is possible to reduce the coach's downtime. This will help the organization to achieve the maintenance as cost effective maintenance. Carretero et al. [15] has performed a case study for applying the RCM technique on a large-scale railway infrastructure network. Using this technique, it is possible to overcome the traditional maintenance approach of relying and following the periodic inspection and the 'know-how' of maintenance. They concluded that the RCM would be a promising technique from the beginning of the RAIL project due to technical insights in order to optimize the maintenance processes, to encourage the maintenance staff for new approach and for their job enrichment, for better and structured approach with well-documented analysis and clear decision diagrams. Marquez et al. [16-18] has performed a case study for the assessment of wear in railway points using the unobserved component model or using a remote monitoring system, This study was to understand the behavior of the track from sitting at a remote location and based on this information a proper action can be taken. They concluded that there developed model is helpful to determine the source of the problem and from where it is arising, based on the designed robust algorithm for detecting wears in the point mechanism. They were able to see the significant correlation between a reference curve which was designed during the study and the real time data coming from the point after each movement. The system was also able to detect the wear and was able to provide the behavior of the worn-out points.

Cheng et al. [19] has studied intelligent reliability centered maintenance to improve the efficiency of the RCM technique. They used Artificial Intelligence (AI) technology to check if the historical record of the RCM tool can be analyzed and can be implemented in the latest equipment. By using this they want to study that if the RCM analysis process can be simplified or the repetition can be avoided. They concluded that the intelligent RCM analysis (IRCMA) can be helpful to improve efficiency and quality of the RCM analysis, the introduction of the artificial intelligence in RCM analysis has given a power to RCM analysis, and also have given a hope to use the RCM analysis on military and civilian systems. D'Addio et al. [20] has performed a research on probabilistic approach which was bsed on Stochastic Petri Nets to effectively implement a Reliability Centered Maintenance (RCM) approach to the high-speed vehicle electrical drives and to know the potential benefit of this on the traditional maintenance approach. They concluded that the Reliability centered maintenance approach can be used to optimize the life cycle cost of the transportation system, the life cycle cost includes the cost of spares, cost of maintenance crew, cost of the periodic maintenance and RAMS parameter of the equipment. Lee et al. [21] had performed a study to integrate the Reliability centered maintenance with the computerized maintenance management system, this was done to understand that if this integration will help the maintenance managers to take the decision with less effort and in an automated manner based on the reliability assessment. They concluded that the integration of the RCM and the CMMS was successful and they were able to automate the data gathering and an automated web based application provided the clear and concise information for the engineers and maintenance managers, this also helped to reduce the intensive data gathering and then manual processing of the raw data.

Bae et al. [22] has done a reliability centered maintenance analysis on the electrical motor unit subsystems to optimize the maintenance cost, maintenance time and finally the maintenance reliability. They used the maintenance cost function, failure rate, MTBF and AMSAA model in order to perform this analysis. They concluded that by following the RCM based optimization model the maintenance cost was reduced drastically, this analysis also presented that the RCM based optimization model is an efficient model for effective maintenance planning even if the cost and safety of the staff, passengers and equipment was considered. Niu et al. [23] has done a study to optimize the maintenance cost using the condition-based monitoring and reliability centered maintenance. During this analysis data fusion technique was used to improve the condition monitoring, assessment of the equipment and prognostics. They concluded that the system 
which was used to perform the condition monitoring of the equipment was able to optimize the cost by identifying the critical components for operation and associated failures and maintenance related to it. They also concluded that use of data fusion strategy also helped to increase the preciseness of the condition-based monitoring of the equipment.

\section{METHODOLOGY}

This study is implemented on the most critical assets of any railway systems, the point machine and the signaling system which are electrical and electronic systems are considered as heart of the railways system. The remote conditioning monitoring of these parameters will be measured by various transducers which will be logged in the data loggers and then it will be send to database server and from the database server it will be fetched by an application to show these data in graphical formats.

\section{EQUIPMENT TO BE USED}

Current sensors: The current transducers (CTs) for switch machine monitoring are located inside the CTF cabinets in the SER as shown in Figure 3. Once the CTs are installed, the required drive cables are rerouted through the Hall-effect clamps on the transducers.

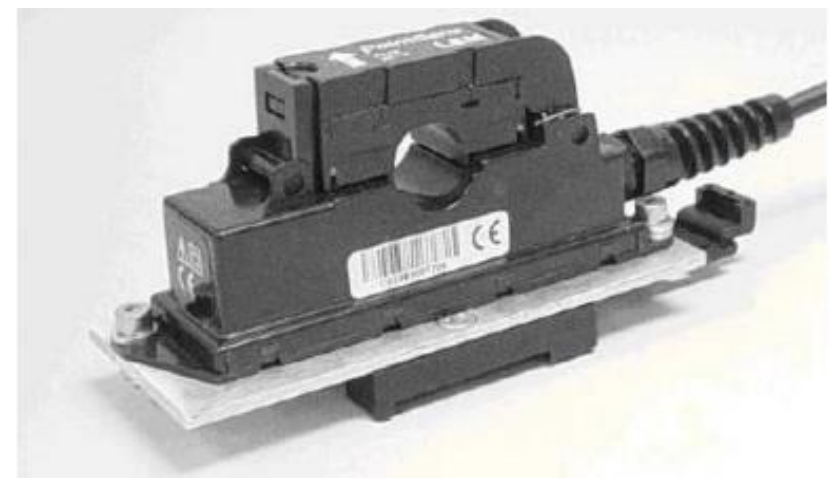

Figure 3. Current sensors

Voltage Transducers: The supply voltage runs at $230 \mathrm{~V}$ AC and does generally not fluctuate except for when the rack is powered down at which point it drops to zero. It is monitored using CR4620 device. The wiring schematic of the voltage transducers is as shwon in Figure 4.

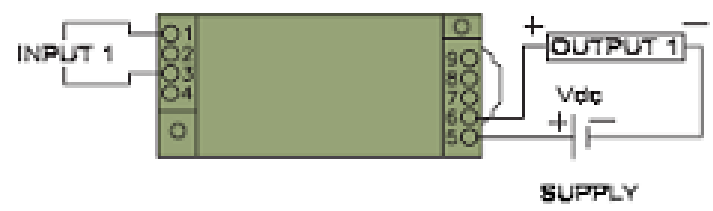

Figure 4. Wiring schematic of Voltage transducers

Temperature sensors: There is a temperature sensor installed in each of the VCC racks located in the various depot and stations across the network. The temperature inside the VCC racks tends to be around $10^{\circ} \mathrm{C}$ higher than the room temperature which makes them between $25^{\circ} \mathrm{C}$ and $33^{\circ} \mathrm{C}$ dependent on rack type and location as shown in Figure 5.

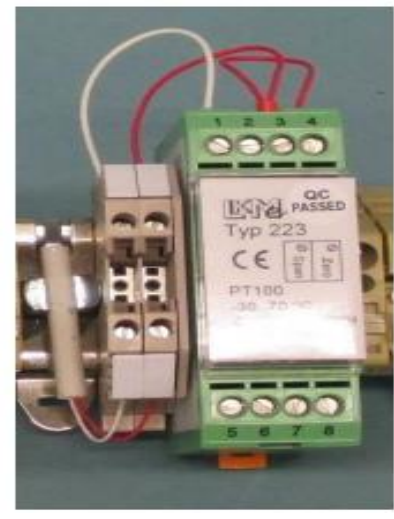

Figure 5. Temperature sensors

Earth Leakage sensors: Earth Leakage sensor is used to detect the leakage from any of the circuit, the resistance value is set at the time of installation, which is based on the circuit on which the sensor is being installed, the parameters can be set in the sensor and then it can be connected with the circuit, when the resistance of the grounding path is going below the set parameter then the sensor detect it and generates the alarm and is as shown in Figure 6.

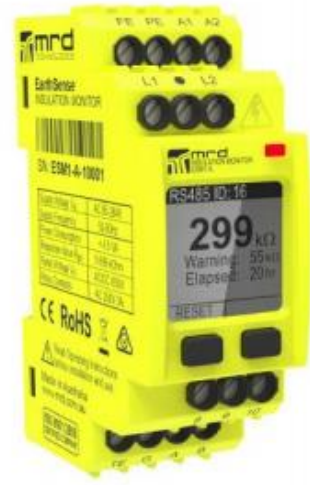

Figure 6. Earth leakage sensors

Data logger: The Mini-Logger 2 (Refer Figure 7) module comes equipped with an LCD screen and set of buttons to allow you to perform various functions locally without the need for a computer. There are status screens that will display information about the logger (IP address, version numbers etc.) and menu screens that are used to setup and configure the logger.

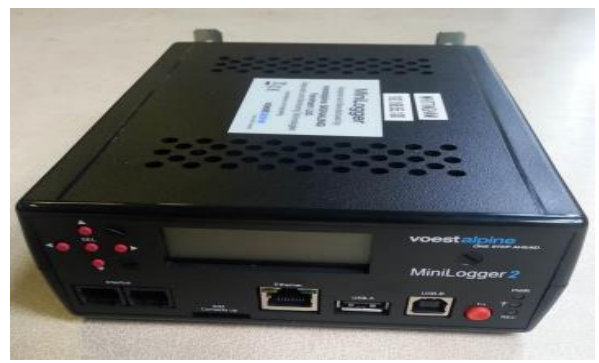

Figure 7. Data logger

Ethernet switch: Ethernet switch is used to connect the data loggers with the network backbone, and the logger's output are sent to the servers via the Ethernet switches as shown in Figure 8. 


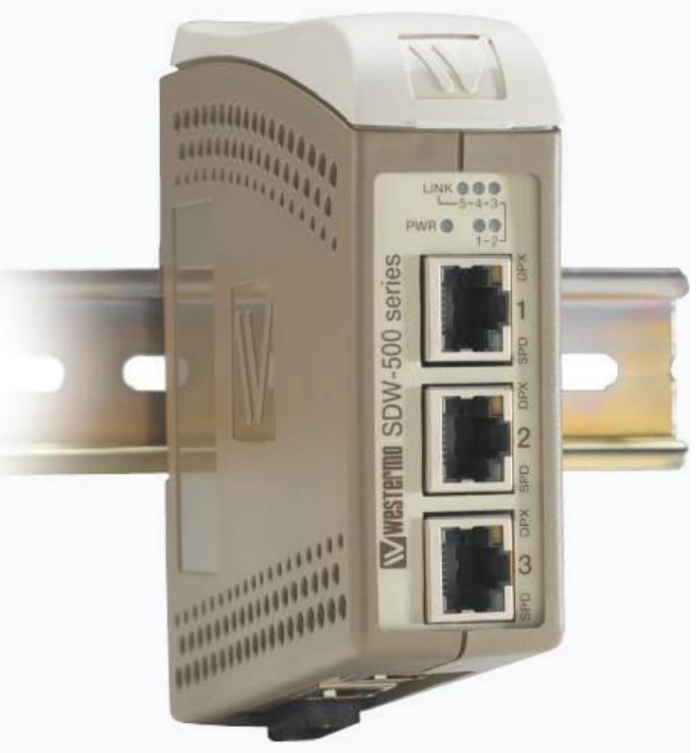

Figure 8. Ethernet switch

Rail temperature sensors: The rail temperature sensors (Refer Figure 9) are used to sense the rail temperature, this is required to check during summers, as the temperature can go beyond a certain level which in turn changes the characteristics patters of stress and strain in the rail. Hence, the rail temperature is being monitored regularly.

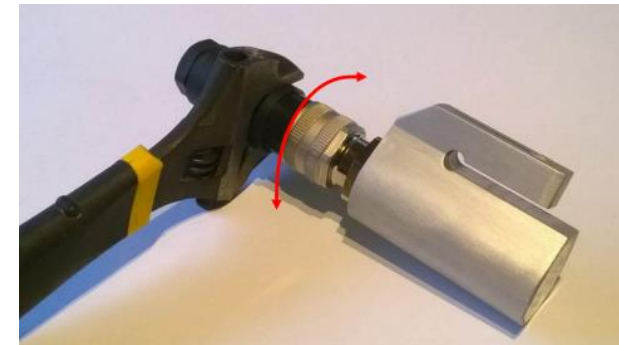

Figure 9. Rail temperature sensors

\section{RESULTS AND DISCUSSIONS}

\section{Output of the condition monitoring tool}

The condition monitoring tool monitors various parameters, some of them are discussed below

\section{Point operating current monitoring}

The point moves whenever there is a train reversal or train changes the track. During the movement of the point, the point control system commands the point to move from one position to another position and the point motor receive commands from the control circuit and operate from one end to another end. While operating from one position to another it unlocks first, moves and then locks at the last.

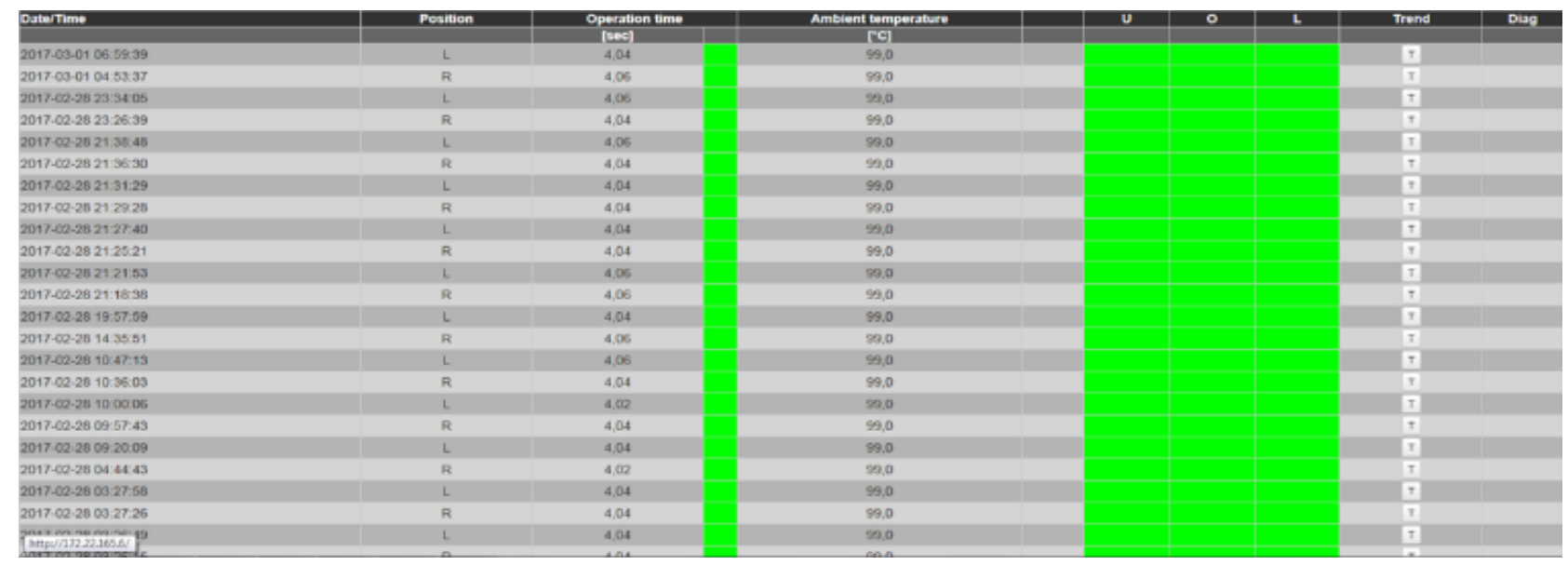

Figure 10. Current graphs data

\begin{tabular}{|c|c|c|c|c|c|c|c|c|}
\hline pretringe & Forren & $\begin{array}{l}\text { Operabon time } \\
\text { [sec) }\end{array}$ & $\begin{array}{l}\text { Amstent remparatoro } \\
\text { icl }\end{array}$ & u & 0 & $L$ & Trend & Deg \\
\hline $2017-02.2801 .13 .14$ & L & 4,56 & $n, 0$ & & & & $T$ & \\
\hline $2017-02.2801 .1259$ & R & 2,90 & $n, 0$ & & & & $\pi$ & D \\
\hline 2017.02 .2801 .12 .44 & L & 7.88 & 99,0 & & & & $T$ & D \\
\hline 2017.022721 .21 .51 & R & 2.20 & 99.0 & & & & $\pi$ & D \\
\hline 2017.02 .2721 .21 .36 & $\mathrm{t}$ & 7.94 & 99.0 & & & & 7 & 0 \\
\hline 201702.2721 .21 .22 & $R$ & 2.16 & 99.0 & & & & 7 & D \\
\hline 2017.022721 .14 .45 & $\mathrm{t}$ & 7.90 & 99.0 & & & & 7 & 0 \\
\hline $2017.02-2721.1430$ & $\mathbf{R}$ & 2.18 & 99.0 & & & & 7 & ह \\
\hline $2017-02.2721 .1646$ & $\mathrm{~L}$ & 7,90 & $\$ 20$ & & & & 7 & D \\
\hline $5017-02.2721 .1344$ & $\mathrm{R}$ & 2.10 & $m .0$ & & & & $\pi$ & 0 \\
\hline $2017-02.27211326$ & L & $7, m$ & $m .0$ & & & & $T$ & 0 \\
\hline Fort-02.27.21 13.11 & R & 2.16 & n. & & & & $T$ & D \\
\hline $2017-0222721.11 .04$ & L & 7,90 & $\boldsymbol{n}, 0$ & & & & $T$ & 0 \\
\hline $2017-02.2721 .10 .49$ & R & 2,14 & n.0 & & & & $\pi$ & 0 \\
\hline $2017-02-2721.1034$ & L & 7,90 & n.0 & & & & $T$ & D \\
\hline $2017-02-2721.0959$ & R & 2,16 & 9,0 & & & & $\pi$ & D \\
\hline 2017.02 .2721 .09 .44 & L & 7.90 & 99,0 & & & & $T$ & D \\
\hline $201702-2721.0929$ & R & 2,20 & 99.0 & & & & 7 & 0 \\
\hline $201702.2721 .08 \cdot 17$ & $\mathrm{~L}$ & 7.90 & 99.0 & & & & 7 & 0 \\
\hline 201702.2721 .0602 & R & 2.18 & 99.0 & & & & $\pi$ & D \\
\hline 2017.02 .27 .21 .07 .47 & $\mathrm{t}$ & 7.90 & $m .0$ & & & & 7 & $D$ \\
\hline $2017 \cdot 02.27 .210700$ & R & 2.20 & 99.0 & & & & 7 & D \\
\hline $2017.02 \cdot 27 \cdot 21.0650$ & L & 7.96 & 9.0 & & & & 7 & 0 \\
\hline
\end{tabular}

Figure 11. Ambient temperature measurements 


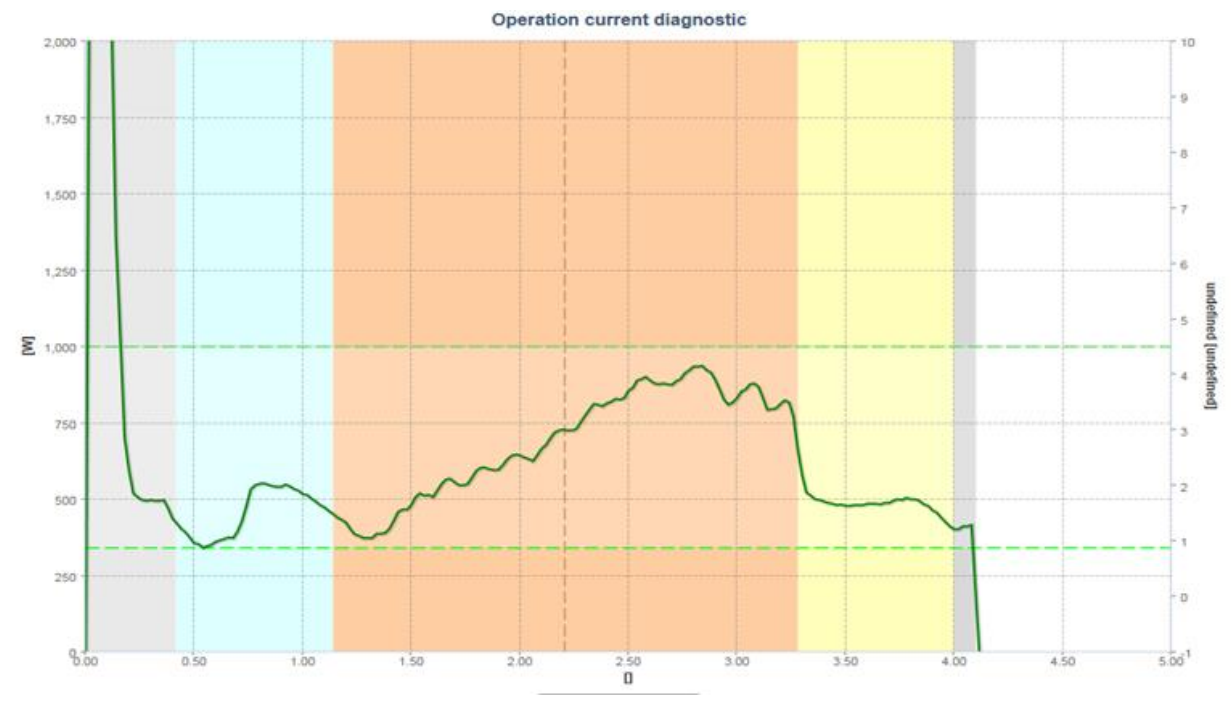

Figure 12. Current diagnostic

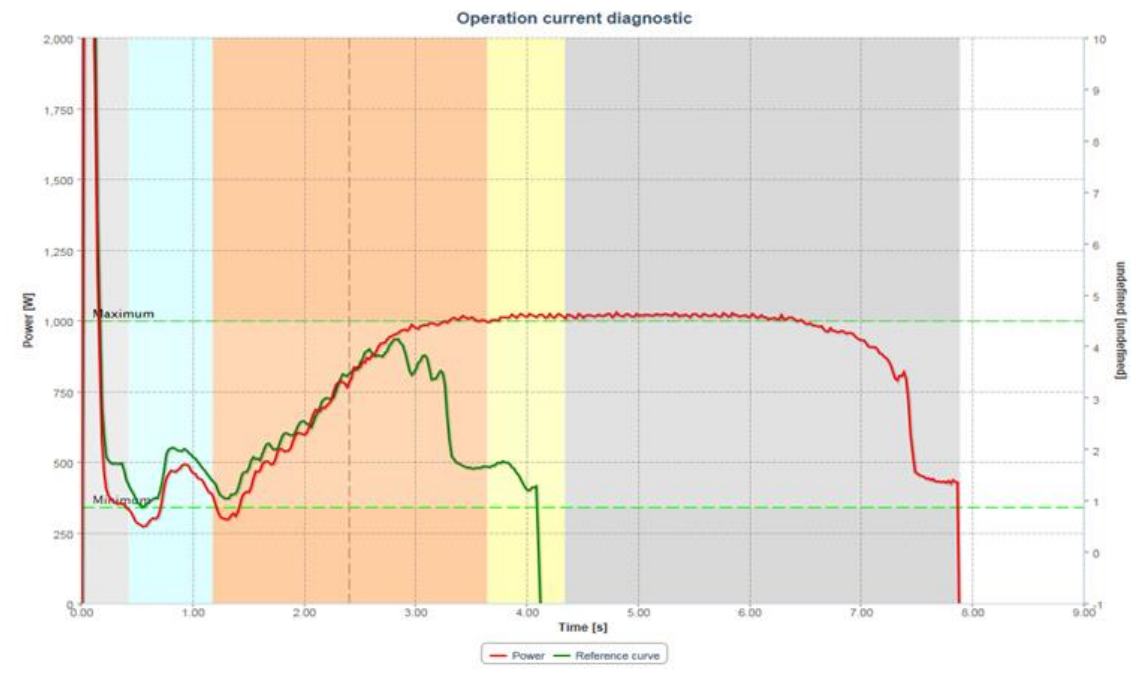

Figure 13. Current diagnostic comparison

Current drawn during the operation is a crucial parameter for condition monitoring of the point, the current of the point motor is as per the physical/Mechanical condition of the point, the current values are different from each of the movement (Refer Figure 10 and Figure 11). The movement current is being monitored for each of the movement, initially the currents graph/ curve after a maintenance is set as the reference curve (Refer Figure 12 and Figure 13).

\section{Current monitoring and voltage monitoring}

This is used to monitor the critical current and critical voltages in the systems, a defined range for the voltages is set if the measured voltages go beyond the limit it generates the alarm for the operator (Refer Figure 14). This monitoring is required to check the inrush current, overcurrent and loading in the system, the monitoring of the current helps the maintainer to establish the root cause in case of the failure due to power related issues.

\section{Power monitoring}

This is used to monitor the critical voltages in the systems, a defined range for the voltages is set if the measured voltages go beyond the limit it generates the alarm for the operator.

\section{Temperature monitoring (Equipment/Room/Rail)}

Temperature of the equipment racks, equipment rooms and rail temperature are being monitored, this gives the edge to the maintenance service desk and to act upon high temperature, this reduces the tireless job of the maintainer to go to each site and measure the temperature (Refer Figure 15 and Figure 16).

\section{Outcome of the monitoring}

The outcome of the monitoring railways is shown in Figure 17. From this graph it is possible to identify the operations as well as irregularities at all the stations.

\section{Other locations conditioning monitoring}

The current of the track circuit can be measured continuously and can be monitored from a remote location; the degradation of the current in the circuit can be identified well before the failure and can be act upon. The current track circuit used for conditioning monitoring is as shwon in Figure 18. 

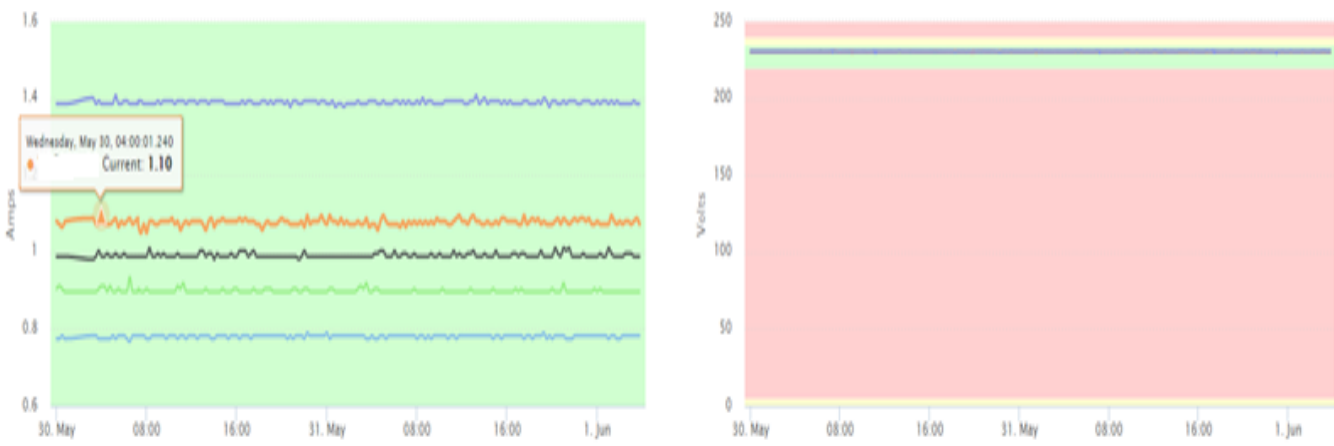

Figure 14. Current trends and voltage trends

Rack Temperature Trends

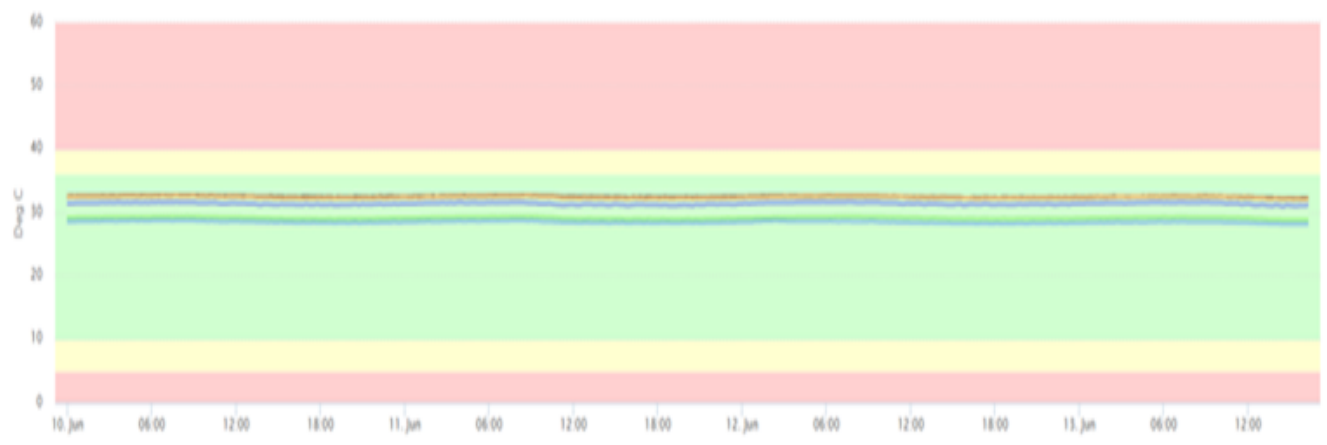

Figure 15. Rack Temperature Trends

All Rail Temperature Trends

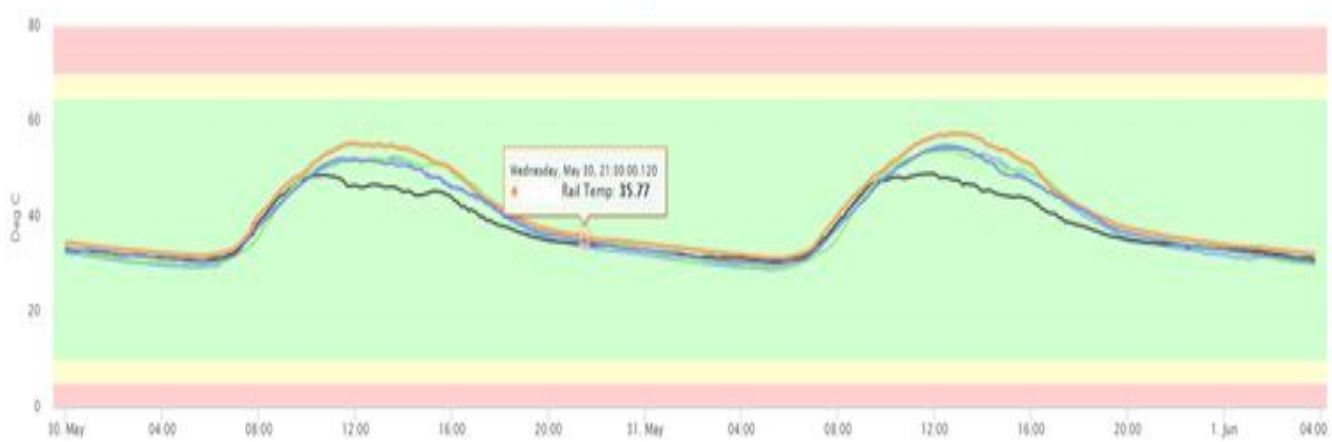

Figure 16. Rail temperature trends

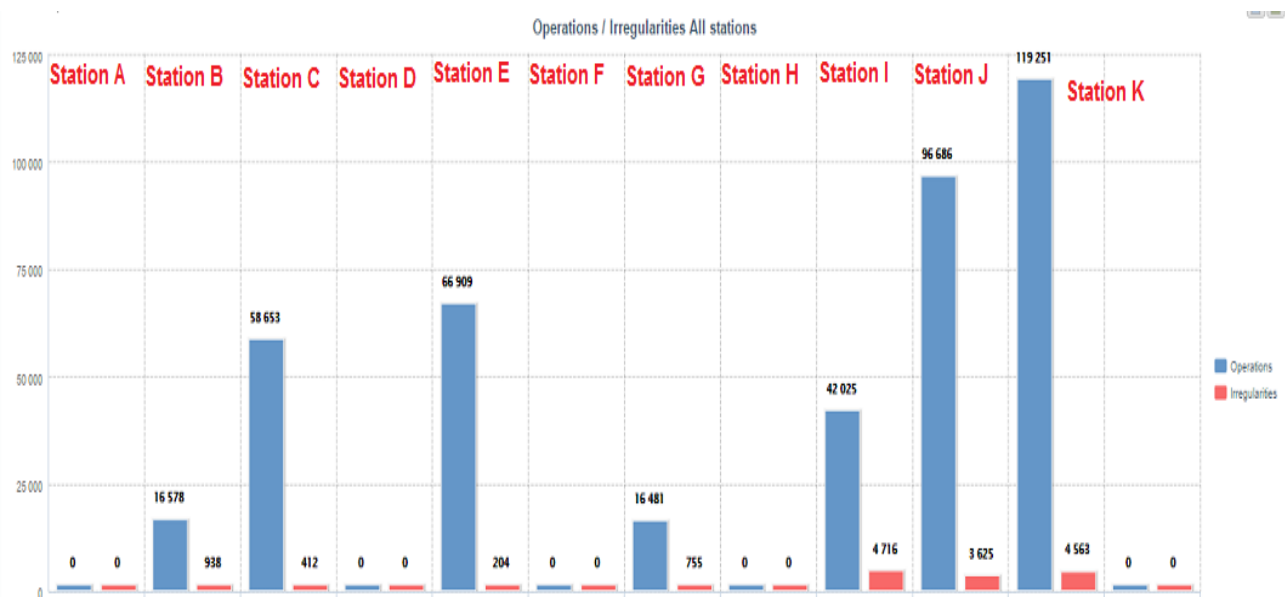

Figure 17. Graph of operations versus irregularities 


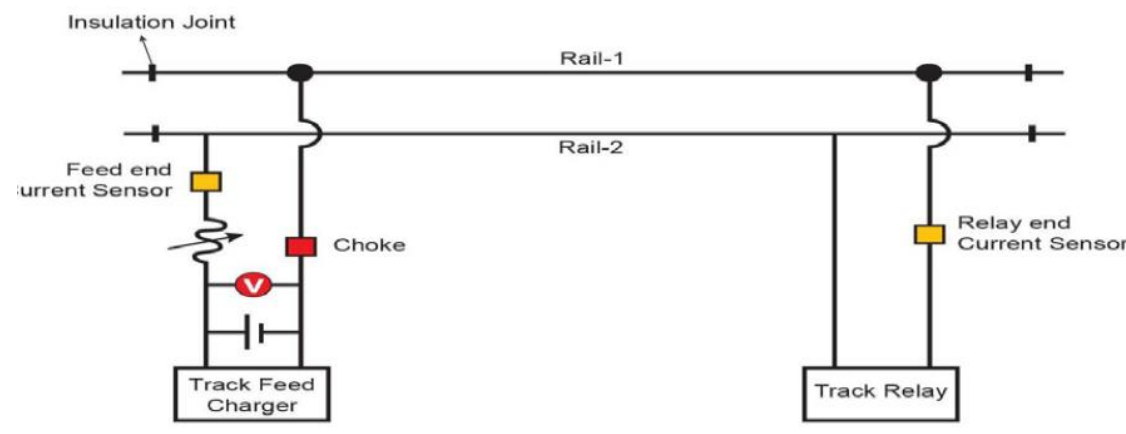

Figure 18. Track circuit

\section{UPS battery health monitoring}

The measurement of the UPS battery is a challenge for the maintenance teams, in railway operation there are multiple UPSs at every station, having maintenance personal for this huge number of assets will have a huge cost impact on the rail operation, the battery voltages in sets and for the individual battery can be monitored using the condition monitoring equipment, this will definitely reduce the opex of the equipment (Refer Figure 19).

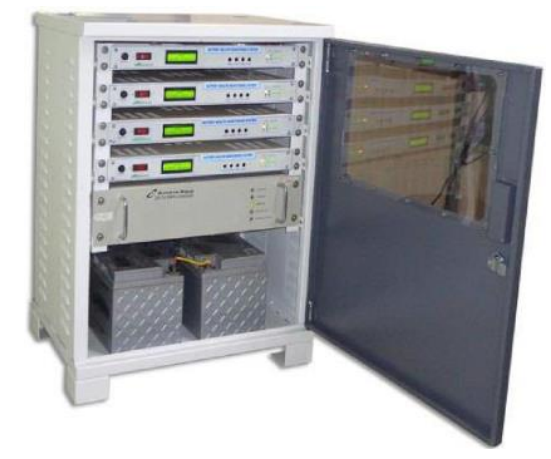

Figure 19. UPS battery used in railway systems

\section{Rails system controllers Input Voltage and Current monitoring}

There are various controllers/microprocessors are being used, the power supply of these equipment can be monitored to make sure that if there is any degradation in the performance of these assets than it can be replaced before the actual failure.

\section{Vibrations of trains Bogie and Wheel health monitoring using Acoustic camera}

The vibration noise of all the mechanical equipment can be monitored using the acoustic camera, which can be installed in a bay and can relate to the condition monitoring equipment to monitor the trains remotely. Apart from this the power monitoring systems, Fuse monitoring system when redundancy is in place and Earth leakage monitoring for various equipment have been used in metro railways systems.

\section{Benefits of condition monitoring tool over the traditional maintenance approach}

Using condition monitoring it is possible to display the online status of equipment health, Reduction of maintenance time and cost, troubleshooting can be easy if configured as per the maintenance requirement, elimination of the unwanted maintenance, gives more insight of the equipment to the maintenance team.

\section{Cost and value}

Based on above literature review, it is observed that it is difficult to compare production cost as well as maintenance cost. Also, there is no clear model in order to compare the cost involved. So the first approach based on cost is that companies prefer to increase the number of resources as well as to invest money in offline condition as well as to increase some online condition monitoring where safety is at most important. The second approach based on cost is that the companies want to invest more money in online condition monitoring by giving less resources. But they need to track the information from the online system and these data need to be analyzed using experts. So, both these approaches need to invest cost for tools and instrument, education as well as training by considering the time during implementation of CBM. But from the research it is also known that collecting the data and analyzing these data requires more time and the paybacks from these CBM system requires time. So, based on above main challenges the companies are putting their effort to implement CBM techniques which require high competency in order to implement these techniques effectively. Also, support from the management plays an important role as well as to change the working culture of the companies to proactive strategies. From this it can be stated that these initiatives will support companies for future success in implementing CBM in this competitive environment.

\section{CONCLUSIONS}

Based on the study performed in the reliability centered maintenance the following conclusions can be drawn.

1. Reliabilility centered maintanance plays an important role in case of railway systems and it is possible to detect fault using this approach. Hence, it can be concluded that Reliability centered maintenance is having more benefits in health monitoring of the system as compared to traditional approach systems.

2. The vibration, noise of the equipment generated in case of railway systems can be monitored using Acoustic camera etc.

3. For those companies who have already implemented reliability centered maintenance, the support from the management support is key factor. There main concern is 
to have enough resources and competence area both offline and online CBM techniques. The rest of the companies who are working with CBM tools and techniques, even a small implementation of offline condition monitoring is considered as CBM.

4. The companies have started considering the problems associated with the existing machines and to select appropriate CBM techniques. But they require correct tools as well as competence in measuring and analyzing these data.

5. Further research is to continue the full process of CBM in the manufacturing industries including processing of data as well as decision making.

6. The continuation of this research on some of the critical machines at the manufacturing company should be taken as a pilot study and can demonstrate how these practices are applicable in reducing the cost in case of manufacturing industry.

\section{REFERENCES}

[1] Cotaina, N., Matos, F., Chabrol, J., Djeapragache, D., Prete, P., Carretero, J., Garcia, F., Perez, M., Pena, J, M., and Perez, J, M., (2000). Study of existing reliability centered maintenance (RCM) approaches used in different industries, Universidad Politecnica de Madrid (Technical Report).

[2] Marten, F.A. (2010). Reliability centered maintenance: A case study of railway transit maintenance to achieve optimal performance, MTI Report No. 10-06, Published by Mineta Transportation Institute (MTI), 2010.

[3] Macedo, R., Benmansour, R., Artiba, A., Mladenovic, N., Urosevic, D. (2017). Scheduling preventive railway maintenance activities with resource constraints. Electronic Notes in Discrete Mathematics, 58: 215-222. https://doi.org/10.1016/j.endm.2017.03.028

[4] Liden, T. (2015). Railway infrastructure maintenance A survey of planning problems and conducted research. Transportation Research Procedia, 10: 574-583. https://doi.org/10.1016/j.trpro.2015.09.011

[5] Toit, A.D., Jooste, J.L., Conradie, P.D.F. (2019). Improving the response time for the corrective maintenance of rail infrastructure: a case study of the western cape passenger railway network. South African Journal of Industrial Engineering, 30(1) : 235-247. https://doi.org/10.7166/30-1-1909

[6] Famurewa, S.M., Asplund, M., Rantatalo, M., Parida, A., Kumar, U. (2015). Maintenance analysis for continuous improvement of railway infrastructure performance. Structure and Infrastructure Engineering, 11(7): 957-969. https://doi.org/10.1080/15732479.2014.921929

[7] Noman, M.A., Nasr, E.S.A., Al-shayea, A., Kaid, H. (2019). Overview of predictive condition based maintenance research using bibliometric indicators. Journal of King Saud University - Engineering Sciences, 31(4): 355-367. https://doi.org/10.1016/j.jksues.2018.02.003

[8] Faiz, R.B., Edirisinghe, E., Singh, S. (2018). Predictive maintenance management of rail track. Proceedings of the 3rd International Conference on European Computing Conference, 35-40.

[9] Pedregal, D.J., Garcia, F.P., Schmid, F. (2004). RCM predictive maintenance of railway systems based on unobserved components models. Reliability Engineering and Systems Safety, 83: 103-110. https://doi.org/10.1016/j.ress.2003.09.020

[10] Marquez, F.P.G., Schmid, F., Callado, J.C. (2003). A reliability centered approach to remote condition monitoring. A railway points case study. Reliability Engineering and System Safety, 80: 33-40. https://doi.org/10.1016/S0951-8320(02)00166-7

[11] Ruijters, E.J.J., Guck, D., Noort, M.N., Stoelinga, M.I.A. (2016). Reliability-centered maintenance of the electrically insulated railway joint via fault tree analysis: A practical experience report. Annual IEEE/IFIP International Conference on Dependable Systems and Networks, 46: 663-669. https://dsn2016.sciencesconf.org/

[12] Bertling, L., Allan, R., Eriksson, R. (2005). A reliabilitycentered asset maintenance method for assessing the impact of maintenance in power distribution systems. IEEE Transactions on Power System, 20: 75-82. https://doi.org/10.1109/TPWRS.2004840433

[13] Wang, H.S., Zhang, L., Ma, X.B., Wen, L. (2009). Preliminary study on reliability-centered maintenance of high-speed train. IEEE 978-1-4244-4905-7/09, 633-638. https://doi.org/10.1109/ICRMS.2009.5270113

[14] Rezvanizaniani, S.M., Valibeigloo, M., Asghari, M., Barabady, J., Kumar, U. (2008). Reliability centered maintenance for rolling stock: A case study in coaches' wheel sets of passenger trains of Iranian railway. IEEE 978-1-4244-2630-0/08, 516-520. https://doi.org/10.1109/IEEM.2008.4737922

[15] Carretero, J., Perez, J.M., Fe'lix, Carballeira, F.G., Caldero 'n, A., Ferna'ndez, J., Garcı 'a, J.D., Lozano, A., Cardona, L., Cotaina, N., Prete, P. (2003). Applying RCM in large scale systems: a case study with railway networks. Reliability Engineering and System Safety, 82(3): 257-273. https://doi.org/10.1016/S09518320(03)00167-4

[16] Marquez, F.P.G., Munoz, J.M.C. (2007). Unobserved component models applied to the assessment of wear in railway points. European Journal of Operation Research, 176(3):

1703-1712. https://doi.org/10.1016/j.ejor.2005.10.037

[17] Marquez, F.P.G., Schmid, F. (2008). A digital filterbased approach to the remote condition monitoring of railway turnouts. Reliability Engineering and System Safety, 92(6) : 830-840. https://doi.org/10.1016/j.ress.2006.02.011

[18] Marquez, F.P.G., Munoz, J.M.C. (2012). A pattern recognition and data analysis method for maintenance management. International Journal of Systems Science, 43(6): https://doi.org/10.1080/00207720903045809

[19] Cheng, ZH.., Jia, X.S., Gao, P., Wu, S., Wang, J.Z. (2008). A framework for intelligent reliability centered maintenance analysis. Reliability Engineering and $\begin{array}{lll}\text { System } & \text { Safety, } & \text { 93(6): }\end{array}$ https://doi.org/10.1016/j.ress.2007.03.037

[20] D'Addio, G.F., Savio, S., Firpo, P. (1997). Optimized reliability centered maintenance of vehicles electrical drives for high speed railway applications. Proceedings of the IEEE International Symposium on Industrial Electronics, $7-11$ https://doi.org/10.1109/ISIE.1997.649017

[21] Lee, J., Lee, M.S., Lee, S.H., Oh, S.G., Kim, B.H., Nam, 
S.H., Jang, J.S. (2013). Development of computerized facility maintenance management system based on reliability centered maintenance and automated data gathering. International Journal of Control and Automation, 6(1): 1-12.

[22] Bae, C., Koo, T., Son, Y., Park, K., Jung, J., Han, S., Suh, M. (2009). A study on reliability centered maintenance planning of a standard electric motor unit subsystem using computational techniques. Journal of Mechanical Science and Technology, 23(4): 1157-1168. https://doi.org/10.1007/s12206-009-0305-8

[23] Niu, G., Yang, B.S., Pecht, M. (2010). Development of an optimized condition-based maintenance system by data fusion and reliability-centered maintenance. Reliability Engineering and System Safety, 95(7): 786796. https://doi.org/10.1016/j.ress.2010.02.016 